WellBeing International

WBI Studies Repository

3-1986

\title{
Variation in Piglet Weights: Relationship to Suckling Behavior, Parity Number and Farrowing Crate Design
}

David Fraser

Agriculture Canada

B. K. Thompson

Agriculture Canada

Follow this and additional works at: https://www.wellbeingintlstudiesrepository.org/ontoge

Part of the Animal Studies Commons, Developmental Biology Commons, and the Other Animal

Sciences Commons

\section{Recommended Citation}

Fraser, D., \& Thompson, B. K. (1986). Variation in piglet weights: relationship to suckling behavior, parity number and farrowing crate design. Canadian Journal of Animal Science, 66(1), 31-46.

This material is brought to you for free and open access by WellBeing International. It has been accepted for inclusion by an authorized administrator of the WBI Studies Repository. For more information, please contact wbisr-info@wellbeingintl.org.

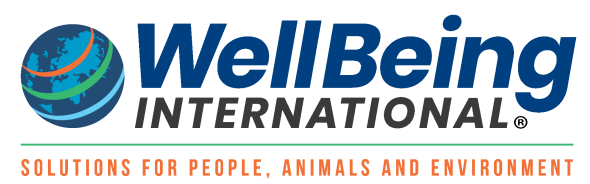




\title{
Variation in Piglet Weights: Relationship to Suckling Behavior, Parity Number and Farrowing Crate Design
}

\author{
David Fraser and B.K. Thompson \\ Agriculture Canada
}

\begin{abstract}
KEYWORDS
piglet, weight gain, suckling behavior, farrowing crate design, parity number

ABSTRACT

Suckling behavior and weight change of piglets were studied during the first 2 wk after birth. Thirty-six litters comprised a balanced comparison of parity number (first or second), litter size $(8,10$ or 12$)$, and two farrowing crate designs, one of which had a low horizontal bar that tended to impede the piglets' access to the udder. Piglets showed the expected preference for the anterior teats although the preference was more apparent in the second parity than in the first. Teat fidelity was most pronounced at the two ends of the udder; piglets occupying the middle positions did more fighting during suckling and missed the milk ejection more often. Within litter variation in 14-day weight increased with increasing parity number of the dam. Initial weight explained $30-40 \%$ of within-litter variation in 14-day weight. Behavioral variables explained $2.6 \%$ of additional variation in first-parity litters, $18.1 \%$ in second-parity litters, and $22.9 \%$ in litters of older sows. Suckling position (anterior to posterior) and teat fidelity (consistency of suckling position) were the two behavioral factors most closely associated with 14-day weight. Mean litter 14-day weight showed the expected effect of litter size, but showed no differences attributable to parity number or farrowing crate design. However, within-litter variation in 14-day weight was greater $(P<0.025)$ in the type of crate that impeded access to the udder. This may have been due to the somewhat higher levels of fighting, and to higher within-litter variance in fighting scores, seen in these crates.
\end{abstract}

Litter-mate piglets, even if they are reasonably uniform in birth weight, will sometimes differ by a factor of 3 or more in weaning weight. Such lack of uniformity can complicate subsequent management, requiring delayed weaning or other special treatment for the low-weight pigs. Furthermore, poor nutrition is a major factor leading to piglet deaths (English and Smith 1975). A sound understanding of why piglets have such variable weight gains could shed light on why so many die.

A number of studies have shown that within-litter differences in piglet weights are influenced by the animals' birth weights and typical suckling positions on the sow's udder (Navratil 1959; McBride et al. 1965; Fraser and Jones 1975: Hemsworth et al. 1976a; Scheel et al. 1971; Majerciak et al. 1977; 
Buchenauer and Dannemann 1979; Fraser et al. 1979; Zschorlich and Ritter 1984a). The results have generally shown that when piglets are $2-3$ wk old, about $30-40 \%$ of within-litter variation in body weight can be explained by variation in birth weight, and an additional $5-10 \%$ by a small tendency toward superior weight gains among piglets using the more anterior teats (McBride et al. 1965; Fraser et al. 1979). With these factors taken into account, $50-60 \%$ of within-litter variation remains unexplained.

Despite the single-minded emphasis on suckling position in earlier studies, there are a number of other behavioral factors that could influence variation in piglet performance. First, piglets tend to return to the same teat (or teat pair) at successive suckling episodes. This teat fidelity begins to develop in the first hours after birth, and helps to reduce the amount of fighting at the udder (Hartsock and Graves 1976). However, teat fidelity is a variable trait, developing more quickly for piglets suckling at the ends of the udder than for piglets using the middle positions (Van Loen and Molenaar 1967; Fraser 1975). Hemsworth et al. (1976b) and Winfield et al. (1974) noted that poor teat fidelity tended to be associated with poor weight gains and large litter size.

Second, despite the regulating influence of teat fidelity, some piglets still engage in prolonged, disruptive fighting during the initial stages of suckling. This type of fighting is more common among large litters and among piglets using the middle teats (Fraser 1975), but its effect on weight gain has not been studied.

Third, the sow's milk ejection is remarkably brief, lasting only about 10-25 sec during the established lactation (Fraser 1980; Ellendorff et al. 1982). Because the sow's mammary gland lacks any appreciable cistern capacity (Turner 1939), milk is available to the piglets only during the ejection itself. The sow's nursing behavior involves several distinctive features that encourage the piglets to be present and sucking throughout the milk ejection (Fraser 1980); however, some piglets repeatedly miss milk ejections, and their milk intake may be correspondingly impaired.

The purpose of this study was to examine whether these various behavioral factors contribute to variation in the weight gains of suckling pigs, with a view to producing a more comprehensive regression model of variation in piglet weights. The data also allow a more extensive examination of some aspects of suckling behavior than has been possible in earlier studies.

The experiment was also planned to test the effect of two farrowing crate designs on piglet performance and behavior. In some farrowing crates, the lowest side bar occupies a horizontal position about $250 \mathrm{~mm}$ above the pen floor (Fig. 1, upper photograph). Depending on the spacing of the bars and the size of the sow, the lowest bar can interfere considerably with the piglets' access to the upper row of teats (Foster 1981; Best 1983). In this experiment we compared suckling behavior and piglet weights in a crate which frequently caused interference with suckling, and in an alternative crate which provided unimpeded access to the udder.

\section{MATERIALS AND METHODS}

The experiment involved 50 litters of Yorkshire pigs from the Animal Research Centre's specificpathogen-free herd at Ottawa. The farrowing facilities consisted of 36 identical farrowing pens measuring $2.1 \times 1.6 \mathrm{~m}$. divided equally among six rooms. Flooring was concrete in the central area and expanded metal to the front and rear of the sow.

The farrowing crates were constructed of round galvanized tubing of 32-mm outside diameter, using a common commercial design. Each side of the crate consisted of three horizontal bars located 970, 690 and $410 \mathrm{~mm}$ above the floor, and a fourth, lowest horizontal bar that could be positioned 200, 250, or 300 $\mathrm{mm}$ above the floor. For each dam, the lowest bar was set at the highest position that still prevented the dam from becoming lodged underneath. This was normally the $200-\mathrm{mm}$ position for gilts (primipara), and 
$250 \mathrm{~mm}$ for older sows. The sides of the crate were $620 \mathrm{~mm}$ apart (outside dimension), leaving an inside dimension of $560 \mathrm{~mm}$ between each pair of horizontal bars. The crates were converted to a "vertical-bar" design by removing the lowest horizontal side bar and installing a series of tubular vertical bars, usually three on each side. The bars were clamped onto the crate sides using J-shaped bolts; they flared outward from the sow at an angle of 25 degrees and caused virtually no interference with suckling (Fig. 1). Sows were moved into farrowing crates about 5 days before farrowing was due. Crates were filled as they became available, and were then converted to horizontal or vertical bars as required. This avoided systematic confounding of crate type with any position or room effects.

The 50 litters consisted of two separate data sets collected over the same period from August 1981 to February 1983. Thirty-six litters (the offspring of 18 dams during their first two lactations) comprised the "balanced data set", and were used for the between-litter comparisons and for the comparison of farrowing crate designs. A cross-over experimental design was used, with half the dams assigned to a horizontal-bar crate for the first lactation and a vertical-bar crate for the second, while the reverse order was used for the remaining dams. During each dam's first lactation, litter size was adjusted to 8,10 or 12 piglets, with six dams at each litter size. In most cases, dams were assigned initially to the litter size closest to the number at birth, so that minimal fostering was needed. In the second lactation, fostering was used to ensure that each sow had the same litter size as in the first lactation. All fostering was done within24 $\mathrm{h}$ of farrowing. Piglets were removed if they had physical abnormalities or if their body weight was $<800 \mathrm{~g}$, as such animals were likely to die before 14 days. Apart from this, piglets to be removed were chosen at random. Piglets to be added were within the weight range of their new litter-mates and differed in age by no more than $36 \mathrm{~h}$.

The remaining 14 litters were the offspring of sows of third or subsequent parity, and were used in the study of Fraser and Lin (1984). Data on these litters had been collected in the same way as for the litters in the balanced data set; hence, the additional animals were included in the within-litter analyses.

Piglets were weighed on days 0 and 14 of the lactation. Day 0 weights were taken at $4-24 \mathrm{~h}$ of age, after any fostering had taken place. Routine management included ear-notching (for individual identification) and clipping the "eye" teeth at the time when the 0-day weights were taken. Water was available to the piglets from birth, and creep feed from 10 days of age, although very little was eaten before the experiment ended at day 14 . Males were castrated at 10 days of age.

Twenty suckling episodes were observed for each litter. These comprised five episodes on four separate days: one of the days 3-4 after birth, one of days 5-6, one of days 8-10, and one of days 12-14. Before each episode, the piglets were removed from the sow's pen for $45 \mathrm{~min}$. and were then returned for 15 min. This procedure normally assured regular suckling at 1-h intervals, as suckling usually began within 1$2 \mathrm{~min}$ of the piglets' return. If the piglets did not suckle within the $15 \mathrm{~min}$ alloted, they were removed for another 15-min period and returned to the sow again. Ink numbers were marked on the piglets' backs for easy identification.

An attendant watched each suckling episode, and recorded the following, with the assistance of a tape recorder:

(1) The time elapsed between the return of the last piglet and the beginning of suckling. Suckling was said to begin when the sow began grunting rhythmically, usually while lying on one side, and when all the piglets (or all that appeared interested in suckling) had assembled on the udder.

(2) The time elapsed between the beginning of suckling and the beginning of milk ejection, judged by the criteria of Whittemore and Fraser (1974). 
Fig. 1. Piglets suckling with a "horizontal bar" farrowing crate (above) in which the lowest bar is hampering the piglets' access to the teats, and with a "vertical bar" crate (below) in which the lowest horizontal-bar is replaced by three angled, vertical bars that allow better access to the udder.
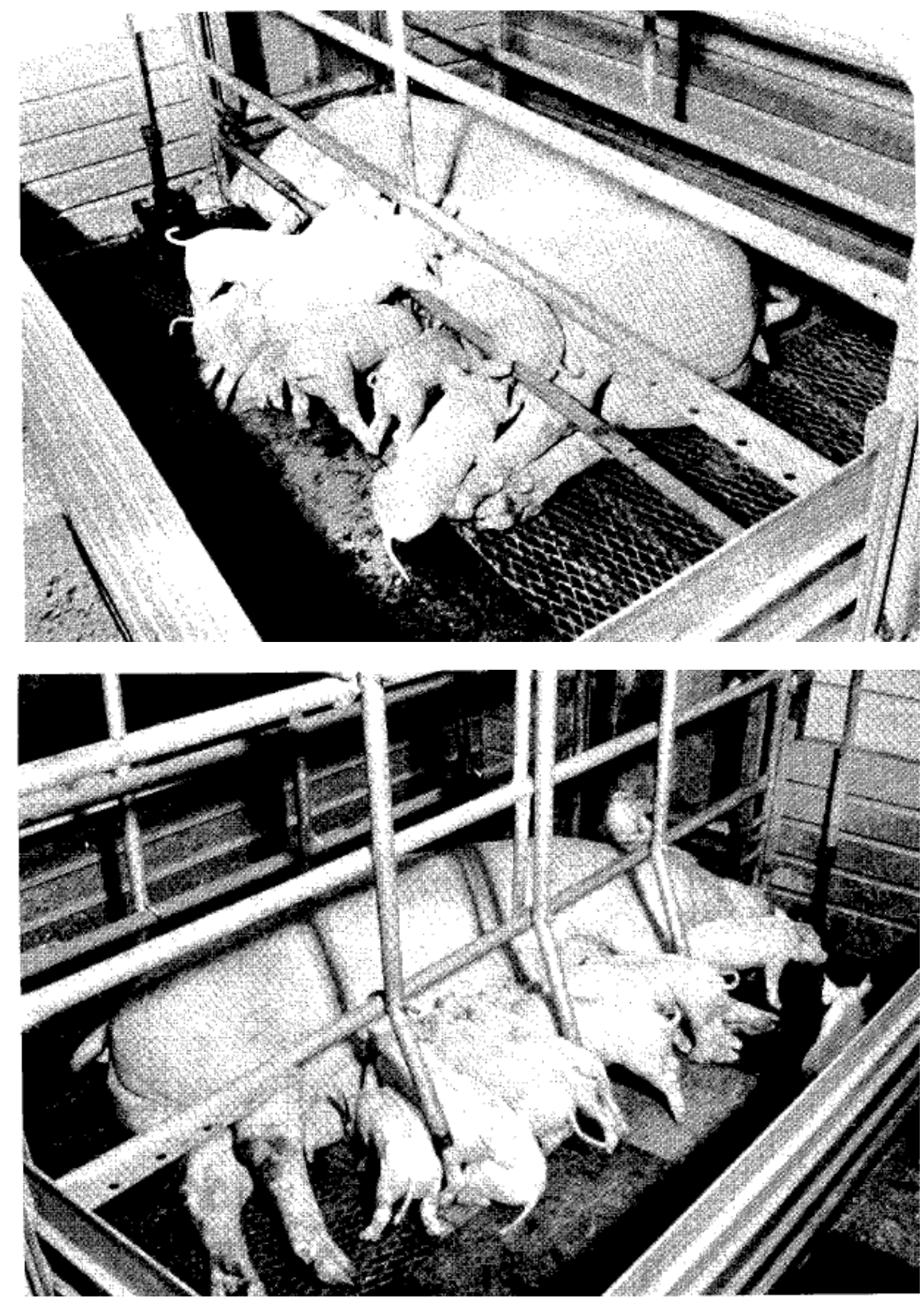

(3) The side on which the sow was lying.

(4) Any fighting among the piglets at the udder, including the identity of the piglets and of the disputed teat. Fighting was said to occur if two or more piglets fought for possession of a teat for $3 \mathrm{sec}$ or more. 
Shorter skirmishes and the general jostling at the start of many suckling episodes were ignored. Fighting was recorded separately for each $15-\mathrm{sec}$ interval of the suckling episode. Two measures were subsequently calculated for each piglet: "incidence of fighting" was the number of suckling episodes (020 ) in which the piglet fought; "fighting score" was the total number of 15 -sec intervals in which the piglet fought, summed over the 20 episodes observed.

(5) The teat occupied by each piglet at the time of milk ejection.

(6) The identity of any piglets that failed to hold and suck on a teat during all or part of the milk ejection. It was also judged whether the piglet missed the milk ejection because of fighting over teats, or for other reasons.

\section{Statistical Analysis}

Differences between litters in the balanced data set (36 litters) were tested by analysis of variance using the following model:

$$
Y_{\mathrm{ijkl}(\mathrm{m})}=\mu+s_{\mathrm{i}}+o_{\mathrm{j}}+(s o)_{\mathrm{ij}}+\epsilon_{\mathrm{ijk}}+p_{\mathrm{l}}+c_{\mathrm{m}}+(s p)_{\mathrm{il}}+(s c)_{\mathrm{im}}+\epsilon^{\prime}{ }_{\mathrm{ijkl}(\mathrm{m})}
$$

Where $\mu$ represents the overall mean; $s_{\mathrm{i}}$ represents litter size $\left(8,10\right.$ or 12 piglets); $o_{\mathrm{j}}$ represents the order effect (whether the horizontal or vertical-bar crate was used first); $p_{1}$ represents parity number (first or second); $c_{\mathrm{m}}$ represents crate type (horizontal or vertical bars); $(s o)_{\mathrm{ij}},(s p)_{\mathrm{il}}$, and $(s c)_{\mathrm{im}}$ represent the interactions of size with order, parity number, and crate type respectively, $\epsilon_{\mathrm{ijk}}$ represents the random component for the $k^{\text {th }}$ sow in the $i j^{\text {th }}$ group, and $\epsilon^{\prime}{ }_{\mathrm{ijkl}(\mathrm{m})}$ represents the random component for the $I^{\text {th }}$ measurement on the $i j k^{\text {th }}$ sow. It was thought that the horizontal bars might influence the piglets' body weights and/or within-litter variation in body weight. Consequently, analyses of variance were applied (i) to mean body weight per litter, and (ii) to within-litter variance in body weight at 14 days, after adjustment for variation attributable to 0-day weight. Means and variances were not weighted according to litter size in order that each litter size would receive equal emphasis. Because within-litter variance was not normally distributed, interpretation was based on the analysis of variance of the logarithms of the variances. However, for clarity of presentation, the means of the untransformed values are shown in the table.

It was noted that some piglets were very consistent in returning to the same teat pair at successive sucklings, but used either the right or left teat of the pair, depending on the side on which the dam lay for nursing. Therefore, a piglet's consistency of teat choice over the 20 suckling episodes was treated as involving two separate factors. A "teat pair consistency score" was calculated for each piglet, to indicate how consistently the animal returned to the same teat pair. The statistic is described by Van Loen and Molenaar (1967) as

$$
C_{i}=\frac{\Sigma K_{\mathrm{ij}}^{2}}{\left[\Sigma K_{\mathrm{ij}}\right]^{2}}
$$

in which $C_{i}$ is the consistency score for the $i^{\text {th }}$ piglet and $K_{\mathrm{ij}}$ is the frequency with which the $i^{\text {th }}$ piglet suckled the $j^{\text {th }}$ teat pair. A separate "side consistency score" was calculated for each piglet as the proportion of the 20 suckling episodes in which the piglet used the side of the udder (right or left row of teats) on which it was more commonly seen. 
Factors influencing within-litter differences in 14-day weight were studied by stepwise regression analysis (applied to all 50 litters), with the variable introduced at each step being the one with the highest partial correlation with the dependent variable. In cases where two variables had similar partial correlations, the process was sometimes repeated allowing the second variable to be introduced first.

Differences were considered not significant if $P>0.05$.

\section{RESULTS}

Of the 500 piglets in the 50 litters, 19 (4\%) died during the experiment. These included 16 piglets from 12piglet litters, 3 from 10-piglet litters, and none from 8-piglet litters. All data from the 19 dead piglets were ignored in the analysis. Only four of the 50 litters had more than one death; hence, mortality had little effect on the litter-size classification of 8,10 or 12 piglets per litter.

Preliminary analyses of variance of individual piglet weights showed a small difference between males and females on day 0 (mean of $1.37 \mathrm{~kg}$ for males, $1.33 \mathrm{~kg}$ for females; $P<0.01$ ), but no difference at 14 days. There was no difference between fostered and unfostered piglets on day 0 or on day 14. Because these differences were small, they were ignored in subsequent analyses.

\section{Between-litter Differences in Body Weights}

Analysis of variance of mean 0-day weight for the balanced data set showed a difference among dams ( $P$ $<0.05$ ), but no significant effect of litter size, lactation number, crate design, or the order term in the crossover design. By day 14, there was a linear trend due to litter size $(P<0.01)$, with lower body weights at the larger litter sizes (Table 1). The trend was more clear with horizontal-bar crates than with verticalbar crates, but the interaction term involving crate type and the linear effect of litter size was not significant. There were no significant differences among dams, between lactations (first vs. second), and no other significant main effects or interactions.

Analysis of variance of within-litter variance in 0-day weight showed no significant effects. By day 14 , however, average within-litter variance in body weight was about twice as great $(P<0.025)$ with horizontal-bar crates as with vertical (Table 2). Mean within-litter variance in 14-day weight was lower ( $P$ $<0.025)$ in the first lactation (0.270) than in the second (0.413). However, the effect was seen clearly only in 10-pig litters, the interaction term (lactation number by litter size) being significant in the analysis of variance $(P<0.05)$. The analysis also showed differences among dams in within-litter variance in 14-day weights $(P<0.05)$.

\section{Between-litter Differences in Behavior}

Means of the 36 litters were used to examine differences between litters in the behavioral traits. All of the traits showed large differences among litters (Table 3). Analyses of variance based on individual piglet data showed greater variation between litters than within litters $(P<0.01)$ for all traits.

The litter means for the behavioral variables were analyzed by analysis of variance using the model described above. There was a linear trend $(P<0.05)$ in missed milk ejections with increasing litter size (means of $0.56,0.63$, and 1.30 missed ejections per piglet per 20 nursings, for litters of 8,10 and 12 piglets, respectively). There was also some evidence of an increase in missed milk ejections in the second lactation (a mean of 1.12 as opposed to 0.62 in the first), but the difference only approached significance $(P<0.09)$. There were no other significant effects or interactions. 
Table 1

Mean body weight of piglets at 14 days (adjusted for 0-day weight), calculated from the balanced data set, shown for two farrowing crate types and three litter sizes

\begin{tabular}{|cccc|}
\hline & \multicolumn{3}{c|}{ Farrowing crate type } \\
\cline { 2 - 4 } Litter† size & Vertical† bars & Horizontal† bars & Both $\ddagger$ \\
\hline & & $\mathrm{kg}$ & 4.19 \\
10 & 4.08 & 4.32 & 4.11 \\
12 & 4.06 & 4.17 & 3.64 \\
All & 3.75 & 3.55 & 3.99 \\
\hline
\end{tabular}

†Standard error of differences (SED) for comparing means of different litter size and the same bar type $=0.185$. SED for comparing means of the two bar types and same litter size $=0.155$.

¥SED for comparing marginal means of litter size or bar type are 0.131 and 0.089 , respectively.

Table 2

Mean within-litter variance in bodv weight of piglets at 14 days (adjusted for 0-day weight) based on the balanced data set, shown for two farrowing crate types and three litter sizes

\begin{tabular}{|cccc|}
\hline & \multicolumn{3}{c|}{ Farrowing crate type } \\
\cline { 2 - 4 } Litter† size & Vertical† bars & Horizontal† bars & Both $\ddagger$ \\
\hline 8 & 0.223 & 0.494 & 0.346 \\
10 & 0.114 & 0.467 & 0.290 \\
12 & 0.350 & 0.426 & 0.391 \\
All & 0.222 & 0.460 & 0.341 \\
\hline
\end{tabular}

†Standard error of differences (SED) for comparing means of different litter size and the same bar type $=0.1791$. SED for comparing means of the two bar types and same litter size $=0.1490$.

‡An approximate SED for comparing marginal means of litter size or bar type are 0.1267 and 0.0860 , respectively.

Although the teat pair consistency score did not appear to be influenced by litter size, crate type or lactation number, there was considerably more variation among sows than within sows $(P<0.05)$. In other words, the consistency score of a sow's first litter tended to be similar to that of the second.

Correlations based on litter means suggested that litters with low teat pair consistency scores tended to have more fighting ( $r=-0.58$ with incidence of fighting, $r=-0.46$ with fighting score), and more missed milk ejections $(r=-0.30)$, especially missed milk ejections attributed to fighting $(r=-0.31)$. Side consistency score was positively correlated with teat pair consistency score $(r=0.60)$, and it showed a negative correlation with incidence of fighting $(r=-0.46)$ and fighting score $(r=-0.30)$. The two fighting measures were closely related $(r=0.90)$, and both measures were related to the number of milk ejections missed because of fighting ( $r=0.75$ for incidence, $r=0.82$ for score).

\section{Nursing Behavior of the Dams}

The 18 dams in the balanced data set nursed 314 times while lying on the right side, 381 times lying on the left side, and 25 times while standing. Some dams showed a strong preference for one side or the other in a given lactation but these preferences did not persist from one lactation to the next. Only three dams nursed while standing, but all three did so at least once in both of the lactations, indicating that this habit, once formed, tended to reappear with a subsequent litter. 
Table 3

Overall mean, range of litter means, and means divided according to farrowing crate type, for seven behavioral traits, based on the balanced data set

\begin{tabular}{|lcccc|}
\hline & & & \multicolumn{2}{c|}{ Means by crate type } \\
\cline { 4 - 6 } Variable & Mean & Range & Horizontal & Vertical \\
\hline Missed milk ejections (fighting) & $0.28 \dagger$ & $0.00-1.33$ & 0.35 & 0.22 \\
Missed milk ejections (other) & $0.58 \dagger$ & $0.00-2.17$ & 0.59 & 0.57 \\
Missed milk ejections (total) & $0.87 \dagger$ & $0.00-3.50$ & 0.94 & 0.79 \\
Fighting incidence & $1.30 \ddagger$ & $0.00-3.75$ & 1.50 & 1.09 \\
Fighting score & $2.38 \S$ & $0.00-7.33$ & 2.94 & 1.81 \\
Teat pair consistency score & $0.69 \uparrow$ & $0.45-0.98$ & 0.70 & 0.68 \\
Side consistency score & $0.82^{\star}$ & $0.56-0.98$ & 0.83 & 0.80 \\
\hline
\end{tabular}

†Mean number of missed milk ejections per piglet in 20 nursings.

¥Mean number of nursings in which a piglet fought, averaged over 20 nursings.

§Mean fighting score per piglet, averaged over 20 nursings.

IMean value of the score representing how consistently a piglet returned to the same teat pair over 20 nursings.

*Mean value of the score representing how consistently a piglet returned to the same side of the udder over 20 nurslngs

The sows differed greatly in the speed with which they began nursing after the piglets were returned $(P<$ 0.02 by analysis of variance applied to the median time to begin nursing calculated for each litter); however, there were no significant differences attributable to lactation number, crate type, or litter size. Sows also differed in the amount of time elapsed between the start of nursing and the start of milk ejection (mean of $82 \mathrm{sec}$, range of 24-350 sec). Analysis of variance, applied to litter medians, showed large differences among dams $(P<0.001)$ and a slightly longer interval in the second lactation than in the first $(P<0.02)$ but no other significant effects.

\section{Regression Analysis of Mean Litter 14-day Weights}

To consider the possible influence of the behavioral variables (including nursing behavior of the dams) on mean litter 14-day weight, a regression analysis was applied to the means, first taking out the variation attributable to the various factors in the design (sows, parity, etc.) and the effect of 0-day weight, and then adding the behavioral variables in a step-wise fashion. The 0 -day weights accounted for $26.5 \%$ of the residual variation; the only other variable of note, total missed milk ejections, accounted for an additional $9.0 \%$.

\section{Factors Associated with High Within-litter Variance in 14-day Weights}

Because litters with horizontal-bar crates had substantially greater within-litter variance in 14-day weight than litters with vertical-bar crates, we attempted to identify behavioral factors that might contribute to high within-litter variance in 14-day weight.

Based on the 36 litters in the balanced data set, correlations were calculated between within-litter variance in 14-day weight (after adjustment for 0-day weight) and within-litter variance in the behavioral variables. The highest correlations obtained were: $r=0.505$ with fighting score, $r=0.368$ for fighting incidence, $r=0.429$ for missed milk ejections due to fighting, and $r=0.494$ for total missed milk ejections (all values based on rank order correlations). In contrast, within-litter variance in 14-day weight was not closely associated with the litters' mean values for these variables. Thus, it appears that uneven 14-day weight was associated with uneven distribution (within a litter) of such behavior as fighting and missed 
milk ejections. Litters with horizontal-bar crates tended to have high within-litter variance in several of these behavioral traits. Within-litter variance in fighting score averaged 17.6 in horizontal-bar crates versus 5.5 in vertical $(P<0.10$ by analysis of variance applied to the logarithms of within-litter variances). The same trend, though again not statistically significant, was seen for within-litter variance in incidence of fighting (2.58 in horizontal, 1.36 in vertical), and in milk ejections missed because of fighting ( 0.60 vs. $0.27)$.

\section{Within-litter Differences in Behavior}

Counts of how often each teat pair was used at the time of milk ejection showed that the piglets occupied the anterior teats more than the posterior ones, with the pattern of decline from front to rear depending on litter size (Fig. 2a). Interestingly, for all three litter sizes, the piglets used the second pair less than the third; for larger litters, there was a similar tendency, albeit less marked, to use the sixth pair less than the seventh.

Fig. 2. Mean number of suckling episodes, out of a total of 20, in which each teat was occupied at the time of milk ejection (parts $a$ and $b$ ) and contested by two or more piglets (parts $c$ and d), averaged over the 36 litters in the balanced data set. Results are shown separately for litters of 8,10 and 12 piglets (parts a and c) and for first- and second-parity litters (pairs b and d).

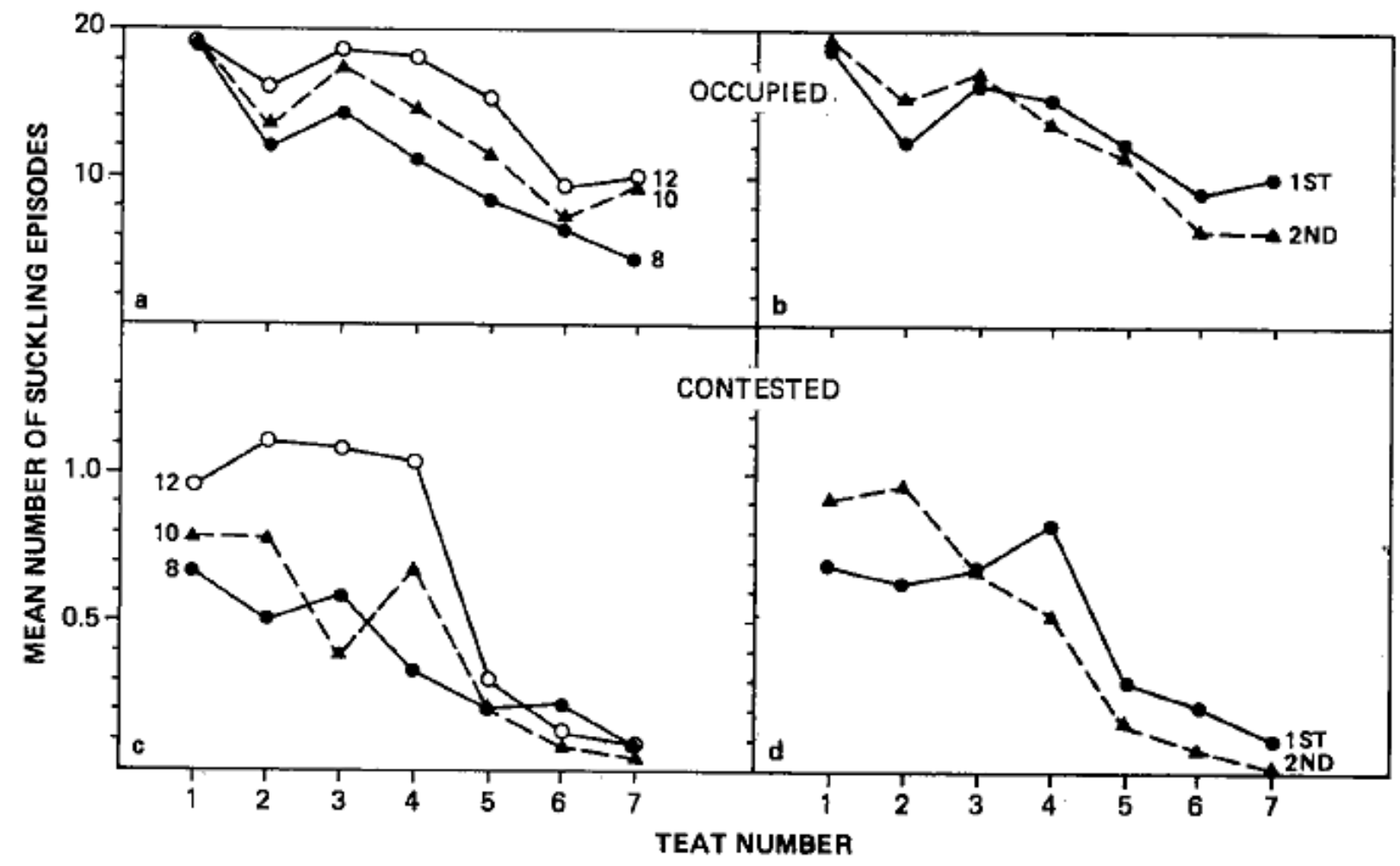

The tendency to use the more anterior teats was more pronounced in the second lactation than in the first (Fig. 2b). In the first lactation, the occupancy rate averaged $80 \%$ for teat pairs $1-3$ as against $59 \%$ for pairs $4-7$. In the second lactation, the comparable figures were $87 \%$ and $48 \%$, reflecting a general shift to the more anterior positions.

To test the statistical significance of these trends, the numbers of the teats that were occupied were averaged to give a "mean teat number" for each litter at each of the 20 suckling episodes observed. 
Analysis of variance showed that mean teat number was larger in the first lactation than in the second ( $P$ $<0.005)$. Furthermore, there was a positive linear trend $(P<0.05)$ in mean teat number with increasing litter size.

Counts were made of the number of sucklings in which a teat was contested. These showed a pattern very similar to that of teat occupancy. The anterior teats were contested more often than the posterior ones; teats were contested more often in the largest litters (Fig. 2c): and contests for teats were more concentrated at the anterior positions in the second lactation than in the first (Fig. 2d).

Consistent use of the same teat pair (as reflected by the teat pair consistency score) was most pronounced at both ends of the udder, and was lowest for piglets using the middle positions (Fig. 3). The side consistency score showed a slight tendency to follow the same pattern (Fig. 3). Conversely, fighting and missed milk ejections were most common among piglets using the middle positions (Fig. a).

\section{Regression Analysis of Within-litter Differences in 14-day Weight}

Stepwise multiple regression analysis was used with all 50 litters to suggest models which relate 14-day weight to 0-day weight and the other variables. Analyses were done on each litter individually, and on litters grouped according to lactation number, litter size and crate type, after adjustment for litter means.

Fig. 3. Mean teat pair consistency score (open circles) and mean side consistency score (closed circles) for the $\mathbf{3 4 8}$ piglets from the balanced data set. Piglets were classified according to "typical teat number", i.e. the teat pair (1 to 7) most commonly used.

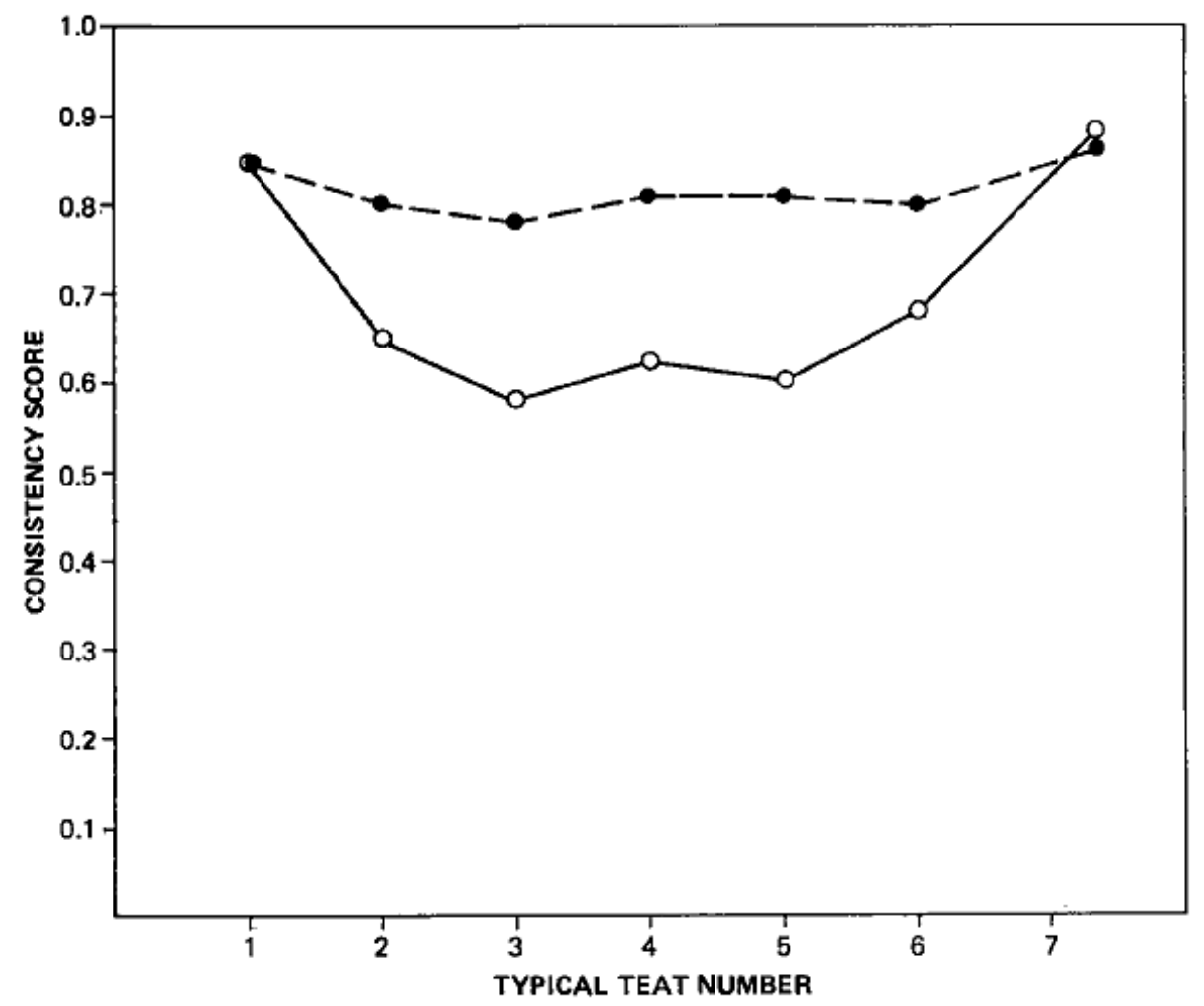

The amount of within-litter variation explained by the regressions differed considerably, depending on the dam's parity number (Table 4). For all three groups of litters shown in the table, 0-day weight accounted for $30-40 \%$ of the within-litter variation in 14-day weight, as expected. For first parity litters, the behavioral 
variables explained little additional variation. Only the teat pair consistency score was related to 14-day weight $(P<0.02)$, accounting for only $2.6 \%$ of additional variation. For second parity litters, both teat number and teat pair consistency score were strongly related to 14-day weights $(P<0.001)$, together accounting for $15.6 \%$ additional variation. After taking 0-day weight into account, these two variables had a similar magnitude of correlation with 14-day weights $(r=-0.37$ and 0.35 for teat number and consistency score, respectively). Missed milk ejections also explained some variation in 14-day weight ( $P$ $<0.05$ ), with misses due to fighting being the major factor.

Fig. 4. Mean number (out of a maximum of 20) of missed milk ejections and mean number of suckling episodes with fighting for the $\mathbf{3 4 8}$ piglets from the balanced data set. Piglets were classified according to "typical teat number", i.e. the teat pair (1 to 7$)$ most commonly used. Results are shown separately for litters of 8,10 and 12 piglets.

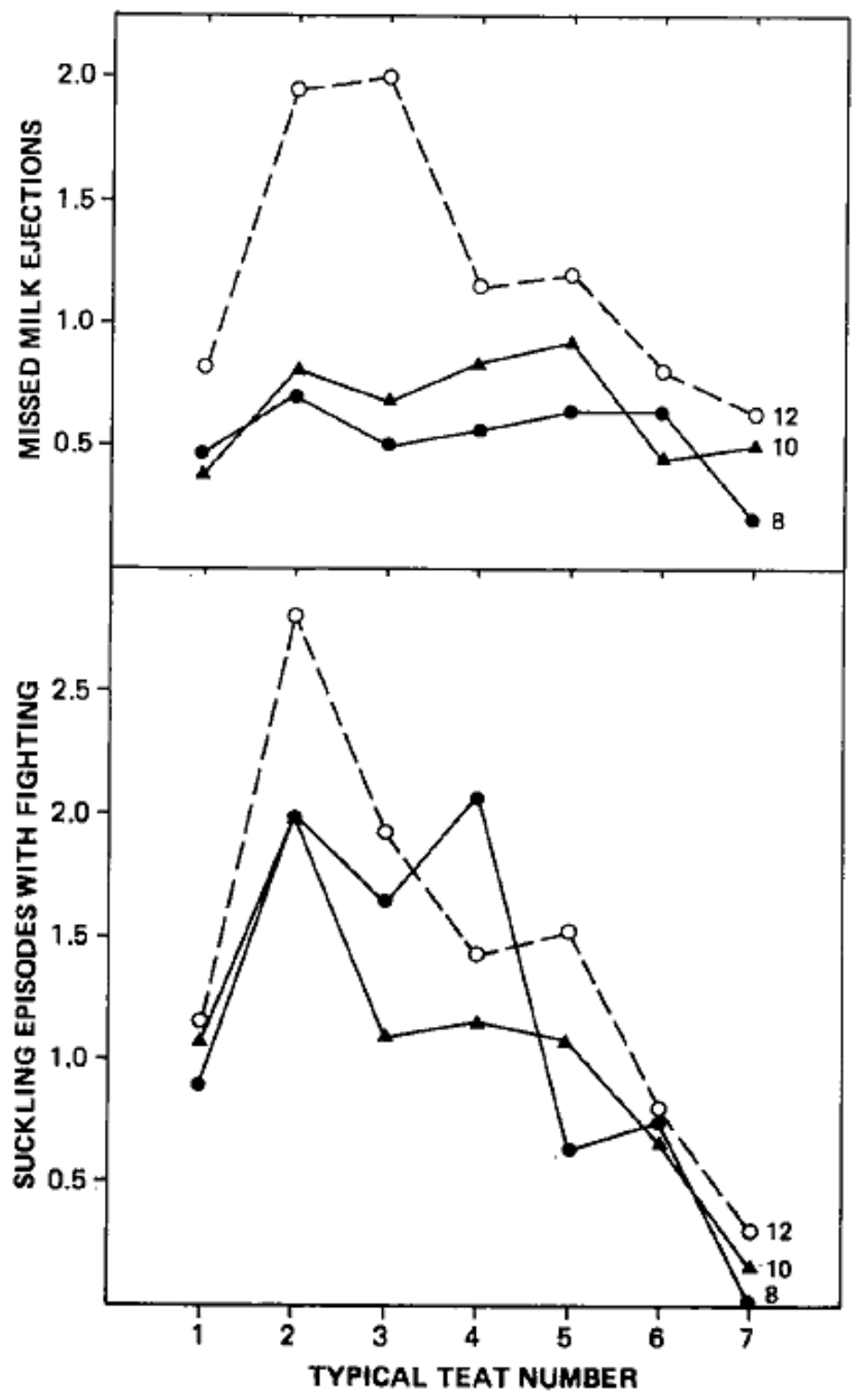

The results for litters of older sows were similar to those of the second parity sows. Again, teat number and teat pair consistency score were strongly related to 14-day weight (partial $r=-0.45$ and 0.50 
respectively, $P<0.001)$, and together accounted for $21.1 \%$ of within-litter variation. Missed milk ejections also accounted for a significant amount of variation $(1.8 \%, P<0.05)$.

The higher percent variation explained in the litters of second-parity and older sows corresponded to a marked increase in the overall variation in the 14-day weights (Table 4). This increase in variation was associated almost entirely with within-litter factors, as the between-litter variation was of similar magnitude for the three groups of litters. In fact, the increase in variation could be accounted for almost completely by the behavioral variables, with the unexplained within-litter variation remaining fairly constant $(0.252$, 0.309 and 0.275 for first-parity, second-parity and older sows, respectively).

Table 4.

Summary of the step-wise regression analyses (within litter) of 14-day weight on behavioral variables for the 18 first- and second- paritv litters in the balanced data set, and for the 14 litters of older sows

\begin{tabular}{|c|c|c|c|c|c|c|}
\hline \multirow[b]{2}{*}{ Variation } & & \multicolumn{3}{|c|}{ Dams from balanced data set } & & \multirow[b]{2}{*}{ Older Sows } \\
\hline & & \multicolumn{2}{|l|}{ 1st Parity } & \multicolumn{2}{|l|}{ 2nd Parity } & \\
\hline \multicolumn{7}{|c|}{ 1. Variance of 14-day weights } \\
\hline Overall & & 0.6463 & & 0.8682 & & 0.9267 \\
\hline Within-litter & & 0.4097 & & 0.6104 & & 0.7317 \\
\hline \multicolumn{7}{|c|}{ 2. Regression coefficients in final equation (standard errors) } \\
\hline 0-day wt. & & $2.24(0.243)$ & & $1.95(0.235)$ & & $1.55(0.210)$ \\
\hline Con. score $†$ & & $0.42(0.220)$ & & $0.91(0.238)$ & & $1.04(0.284)$ \\
\hline Teat no. $\ddagger$ & & $-0.01(0.020)$ & & $-0.11(0.025)$ & & $-0.13(0.031)$ \\
\hline MME§ & & $-0.06(0.036)$ & & $-0.09(0.036)$ & & $-0.07(0.038)$ \\
\hline \multicolumn{7}{|c|}{ 3. Additional percent variation accounted for at each step } \\
\hline \multicolumn{7}{|l|}{ Step } \\
\hline 1 & 0-day wt & 35.8 & 0-day wt & 32.6 & 0-day wt & 39.5 \\
\hline 2 & Con. score & 2.6 & Teat no. & 9.3 & Teat no. & 15.3 \\
\hline 3 & & & Con. score & 6.3 & Con. score & 5.8 \\
\hline 4 & & & MME & 2.5 & MME & 1.8 \\
\hline Total & & 38.4 & & 50.7 & & 62.4 \\
\hline
\end{tabular}

†Teat pair consistency score.

‡Typical teat number, i.e. teat pair most commonly used.

§Missed milk ejections (total).

『At each step, the variable having the highest partial correlation with 14-day weight was added. Only variables with significant mean squares for regression are shown $(P<0.05)$.

Within each parity group, litter size and crate type made little difference to the order in which variables were introduced to the model. However, the regression model tended to explain a little more of the variation in 14-day weight in litters with vertical bars than in those with horizontal bars. Percentage variation explained was 41 vs. $35 \%$ for first-parity litters, 51 vs. $49 \%$ for second-parity litters, and 71 vs. $58 \%$ for litters of older sows.

\section{Characteristics of Piglets with Poor Gains}

Because very slow growth by individual piglets is a significant management problem, a separate analysis was done to identify possible causes of unusually poor performance. Regression analysis of 14-day 
weight on 0-day weight and litter means was used to identify the $10 \%$ of piglets in the balanced data set whose 14-day weights were the farthest below and farthest above their predicted values.

Frequency distributions (Fig. 5) showed that in general, the 35 "worst" pigs used posterior teats more often, had lower consistency scores, and missed more milk ejections, but did not differ greatly in the amount of fighting. However, both the "worst" and "best" groups contained a wide range of values for these variables. In short, there was no single trait or pattern that consistently characterized the underachieving piglets.

\section{DISCUSSION}

With only 36 litters in the balanced data set, the study was relatively unsuccessful at identifying causes of between-litter differences in 14-day weights. Litter size had the expected effect; 0-day weights explained about $27 \%$ of the remaining variation; and total missed milk ejections made a modest further contribution. Differences between crate types, lactation number, the fighting scores, and consistency of suckling position had no appreciable influence on mean litter 14-day weight. Therefore, most of the between-litter variation went unexplained. However, as in the study by Lodge and McDonald (1959), most of the overall variation in piglet weights was within litters, especially with dams of second or later parity (Table 4).

Fig. 5. Frequency distribution comparing the 35 "worst" and 35 "best" piglets (i.e. those whose 14-day weights were farthest below or farthest above the expected values based on regression analysis) for four behavioral variables: typical teat number, teat pair consistency score, total number of missed milk ejections, and fighting score.

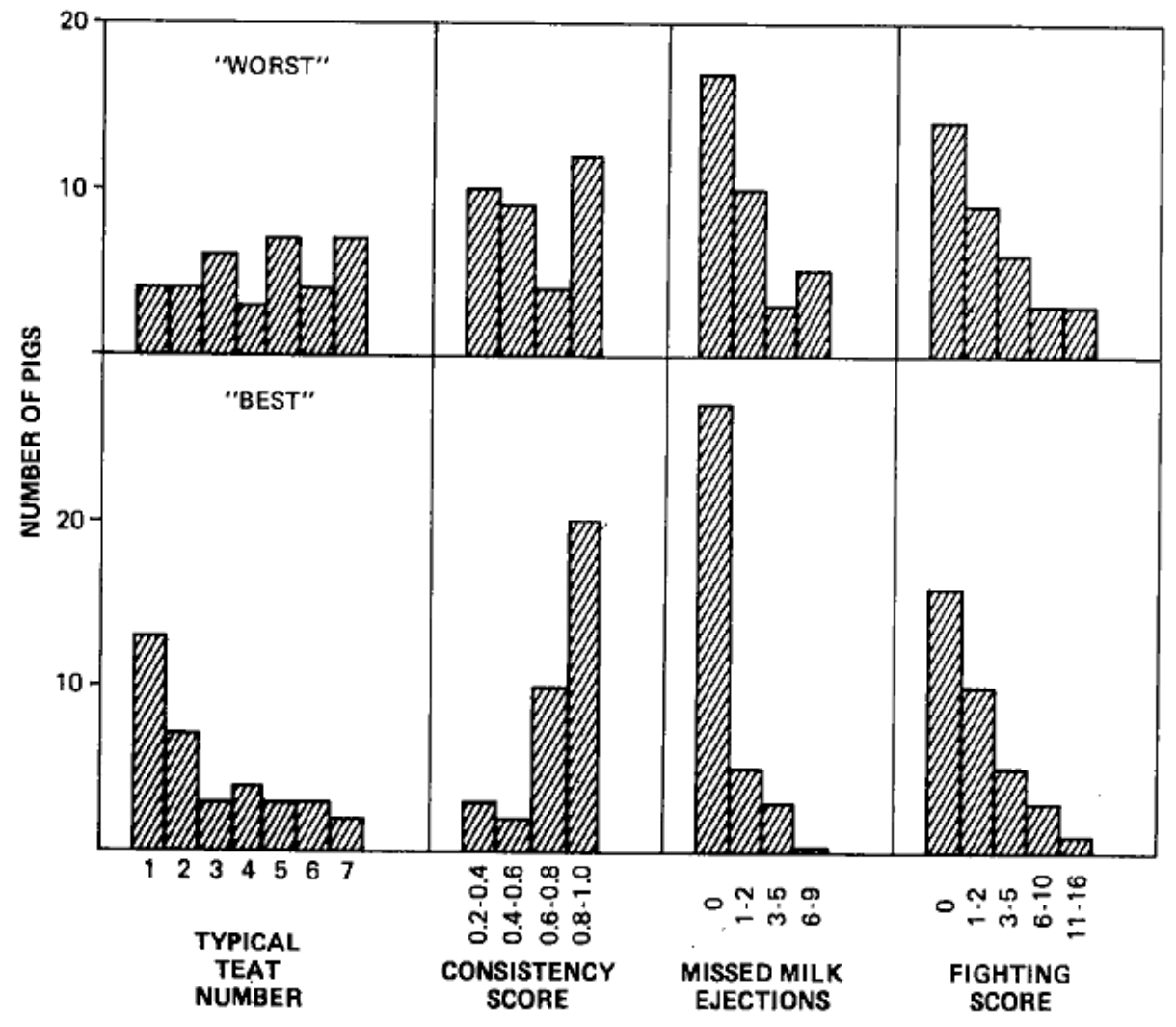

The analysis of within-litter differences in body weight showed considerably more complexity than has previously been recognized. With the same group of 18 dams and the same litter sizes, the amount of 
within-litter variation in 14-day weight increased appreciably from the first to the second parity; and data from the 14 litters of older sows suggest that within-litter variation remains high or continues to increase at later parities. In all three parity classes, 0-day weight explained $30-40 \%$ of within-litter variation in 14-day weight, a result compatible with earlier studies based on 3-wk weights (Lodge and McDonald 1959; McBride et al. 7965; Scheel et al. 1977; Fraser et al. 1979). In the litters of first-parity dams, a piglet s teat number (anterior to posterior) made essentially no difference, and consistency of teat usage had only a very small effect. At subsequent parities, these two behavioral traits became more important, jointly explaining $15.6 \%$ of the variation in 14-day weight for second-parity litters and $21.1 \%$ for litters of older sows. In short, as parity number increased, 14-day weights became less uniform, and behavioral factors became more closely associated with the variation.

It is not clear why within-litter variance in 14-day weight tended to increase with parity number, but the trend may result from increasing variability in the milk production capacity of different teats. As suggested by Haring (1939) and Braude (1948), teats that are well used during the first lactation may subsequently be more productive than those which are not. Hence, differential use in the first lactation may have caused unequal productivity in the next.

This is particularly relevant to the much-discussed "superiority" of the anterior teats. In this study, the anterior-suckling piglets showed no superior weight gains in the litters of primipara, but the first parity litters still showed a clear preference for the anterior positions. This preference could have been due to the shape and spacing of the teats (English et al. 1977), the closer proximity of the sow's grunting (Jeppesen 1982), and the greater ease of extracting the first colostrum from the anterior teats (Fraser and Lin 1984). By the second parity, the litters did show evidence of better piglet performance on the anterior teats, as well as a stronger preference for, and contesting of, the anterior positions (Fig. 2). Again, the greater use of anterior teats in the first lactation may have conditioned them for greater production and greater popularity in the second.

The behavioral trends shown in Figs. 3 and 4 generally reflect a greater stability of teat choice at both ends of the udder. The teat pair consistency score was highest for piglets that typically used teats 1 and 7, and was lower for the piglets on middle teats. Similarly, piglets at the two ends of the udder fought less often and missed fewer milk ejections. These findings generally agree with observations by Van Loen and Molenaar (1961) and Fraser (1975).

The analysis of variance of 14-day weights in the balanced data set showed that some dams raised more uniform litters than others over the two lactations. This could not be attributed to different variances in 0 day weights, as the analysis was adjusted for 0-day weight. The most probable explanation is that some dams consistently achieved more uniform distribution of milk to the piglets, perhaps because the teats were more uniform in productive capacity or ease of draining.

It is not clear why piglet weight gains were positively correlated with consistent use of the same teat pair. The productivity of a teat in a given lactation appears to depend in part on the effectiveness of suckling behavior that the teat receives. Vigorous massage of the teat before milk ejection (Fraser 1984), efficient removal of milk (Wohlbier 1928), and prolonged massage at the end of the suckling episode (Jensen 1984) may all contribute to maintaining a teat's productivity. The best strategy for a vigorous piglet may be to return always to the same teat in order to maintain the productivity of the gland. And, if two piglets of similar size and vigor share one teat pair, then they could presumably use the two sides (right and left) interchangeably, with no disadvantage to either piglet as long as both teats are used at each suckling episode. However, piglets that frequently change teat pairs may fail to maintain the productivity of the teat(s) most commonly used; and pigs that experience poor milk intake, for whatever reason, may try to 
take another piglet's well-maintained teat from time to time. All these factors could contribute to the relationship between teat fidelity and weight gain.

Farrowing crate design had only one clear-cut effect: litters raised with horizontal-bar crates had about twice as much within-litter variance in 14-day weight as litters raised with vertical-bar crates. We have recently obtained a similar result in a subsequent experiment (Thompson and Fraser, unpubl. data). Both studies suggest that the farrowing crate design did not greatly influence the total milk intake of the litter, but did influence the evenness of its distribution to different litter-mates. The behavioral results give no definitive indication of how this happens, but the various measures of fighting were generally higher and showed greater within-litter variance in the horizontal-bar crates (though not at $P<0.05$ ). Perhaps the horizontal bars, in making access to the udder more difficult, essentially increased the effect of competition among litter-mates, so that piglets that had difficulty becoming established on the udder experienced even greater problems when access to the udder was more difficult. With milk intake depressed for such animals, litter-mates with unimpeded access to the teats might be expected to do correspondingly better. However these results do not necessarily indicate a short-coming in all crates designed with low horizontal bars, as access to the udder will depend on the height, spacing, and shape of the bars, on the size of the sow, and on how the sow presents the udder for nursing.

As noted earlier, death before weaning tends to be more common in litters with very uneven body size (English et al.1977; Zschorlich and Ritter 1984b). Our experiment had remarkably few deaths, probably because of the controlled indoor environment, the specific-pathogen-free conditions, and the fact that we did not use piglets of very low birth weight. In a less favorable environment, many of the piglets with very slow growth might well have succumbed. Hence, crate designs or other factors that increase variability in piglet weights may also increase preweaning mortality in many commercial units.

\section{ACKNOWLEDGMENTS}

We are grateful to B. A. Campbell and the staff of the ARC pig unit for their kind cooperation in this work, and to the staff of the ESRI shoo for constructing the bars to modify the farrowing crates.

\section{REFERENCES}

Best, P. 1983. Hot off the press for farrowing, Pig American 8(7): 22-23.

Braude, R. 1948. Some observations on the behaviour of pigs in an experimental piggery. Bull. Anim. Behav. 6: 17-25.

Buchenauer, D. and Dannemann, K. 1979. Untersuchung einiger Einflussfaktoren auf die Saugordnung von Ferkeln. Berl. Munch. Tierarztl. Wschr. 92: 432-437.

Ellendorff, F., Forsling, M. L. and Poulain, D. A. 1982. The milk ejection reflex in the pig. J. Physiol. (Lond.) 333:577-594.

English, P. R. and Smith, W. J. 1975. Some causes of death in neonatal piglets. Vet. Ann. 15: 95-104.

English, P. R., Smith, W. J. and Maclean. A. 1977. The Sow--improving her efficiency. Farming Press, Ipswich, U.K. 
Foster, J. 1981. Crates converted for early weaning. Pig Farming 29(3): 89-91.

Fraser, D. 1975. The 'teat order' of suckling pigs. II. Fighting during suckling and the effects of clipping the eye teeth. J. Agric. Sci. (Camb.) 84:393-399.

Fraser, D. 1980. A review of the behavioural mechanism of milk ejection of the domestic pig. Appl. Anim. Ethol. 6: 247-255.

Fraser, D. f984. The role of behavior in swine production: A review of research. Appl. Anim. Ethol. 11: 317-339.

Fraser, D. and Jones, R. M. 1975. The 'teat order' of suckling pigs. I. Relation to birth weight and subsequent growth. J. Agric. Sci. (Camb.) E4: 387-391.

Fraser, D. and Lin, C. S. 1984. An attempt to estimate teat quality of sows by hand milking during farrowing. Can. J. Anim. Sci. 64: 165-170.

Fraser, D., Thompson, B. K., Ferguson, D. K. and Darroch, R. L. 1979. The 'teat order' of suckling pigs. IIL Relation to competition within litters. J. Agric. Sci. (Camb.) 92: 257-261.

Haring, F. 1939. Einfluss der Erstlingsleistung auf die Hohe der Lebensleistung in der Schweinezucht. Z. Schweinez. 46:. 62-64.

Hartsock, T. G. and Graves, H. B. 1976. Neonatal behavior and nutrition related mortality in domestic swine. J. Anim. Sci. 42: 235-241.

Hemsworth, P. H., Winfield, C. G. and Mullaney, P. D. 1976a. Within-litter variation in the performance of piglets to three weeks of age. Anim. Prod. 22: 351-357.

Hemsworth, P. H., Winfield, C. G. and Mullaney, P. D. 1976b. A study of the development of the teat order in piglets. Appl. Anim. Ethol. 2: 225-233.

Jensen, P. 1984. Acoustic communication during suckling in the pig-its early ontogeny and possible function. Pages 101-104 in J. Unshelm, G. Van Putten, and K. Zeeb eds. Proc. Int. Cong. on Appl. Ethol. in Farm Animals, KBTL, Darmstadt, West Germany.

Jeppesen, L. E. 1982. Teat-order in groups of piglets reared on an artificial sow. I. Formation of teat order and influence of milk yield on teat preference. Appl. Anim. Ethol. E: 335-345.

Lodge, G. A. and McDonald, I. 1959. The relative influence of birth weight, milk consumption and supplementary food consumption upon the growth rates of suckling piglets. Anim. Prod. 1:139-144.

Majerciak, P., Paltarsky, J. and Flak, P. 1977. Mliekova produkcia jednatlivych ceckov prasnic a vyvoj prasiat do odstavu. Polnohospodarstvo 23: 250-258.

McBride, G., James, J. W. and Wyeth, G. S. F. 1965. Social behaviour of domestic animals. VII. Variation in weaning weight in pigs. Anim. Prod. 7: 67-74.

Navratil, B. 1959. Prispevek k studiu vymesovani mleka u prasnic bileho uslechtileho plemene v CSR. 3. Nekteri cinitele ovlivnujici mnozstvi mleka. Sbornik Ceskoslovenske Akademie Zemedelskych ved 4:793806. 
Scheel, D. E., Graves, H. B. and Sherritt, G. W. 1977. Nursing order, social dominance andgrowthinswine. J. Anim. Sci. 45:219-229.

Turner, C. W. 1939. The comparative anatomy of the mammary glands. University Cooperative Store, Columbia, Missourr.

Van Loen, A. and Molenaar, B. A. J. 1967. A behavioural study in pigs. Methodology in measuring the evolution of the teat order. Tijdschr. Diergeneesk. 92: 297-307.

Whittemore, C. T. and Fraser, D. 1974. The nursing and suckling behaviour of pigs. II. Vocalization of the sow in relation to suckling behaviour and milk ejection. Br. Vet. J. 130: 346-356.

Winfield, C. G., Hemsworth, P, H., Taverner, M. R. and Mullaney, P. D. 1974. Observations on the suckling behaviour of piglets in litters of varying size. Proc. Aust. Soc. Anim. Prod. 10: 307-310.

Wohlbier, W. 1928. Stoffwechselversuche zum Eiweissansatz bei saugenden Ferkeln. B. Zeitsch. 202:2969.

Zschorlich, B. and Ritter, E. 1984a. Der Einfluss der Geburtsmassevarianz auf die Ferkelentwicklung in Ammenwurfen. I. Mitteilung: Untersuchungen zur Saugeordnung. Arch. Tierzucht. Berlin 27: 73-83.

Zschorlich, B. and Ritter, E. 1984b. Der Einfluss der Geburtsmassevartanz auf die Ferkelentwicklung in Ammenwurfen. 2. Mitteilung: Die Masseentwicklung der Ferkel. Arch. Tierzucht. Berlin 27: 381-393. 